\title{
ENSO impact on midlatitude circulation patterns in future climate change projections
}

\author{
W. A. Müller ${ }^{1}$ and E. Roeckner ${ }^{1}$ \\ Received 24 October 2005; revised 11 January 2006; accepted 27 January 2006; published 15 March 2006.
}

[1] The remote influence of the leading mode of interannual variability in the Tropics, the El Niño/ Southern Oscillation (ENSO), on the northern hemispheric midlatitude circulation in future climate is investigated. For this, IPCC SRES scenarios of the latest version of the coupled climate model ECHAM5/MPI-OM are used. In ensembles of future climate change projections it is found, that a changing state of ENSO with increased variability has a pronounced influence on the dominant midlatitude circulation pattern, namely the Pacific North America (PNA) pattern and the North Atlantic Oscillation (NAO). More explicitly, in the 21st and 22nd century, a positive (negative) phase of ENSO is more likely followed by a positive (negative) PNA index and negative (positive) NAO index than it is observed in the 20th century. Correlation coefficients between the winter mean Niño3.4 index and the NAO index increase substantially from the 20th century. Citation: Müller, W. A., and E. Roeckner (2006), ENSO impact on midlatitude circulation patterns in future climate change projections, Geophys. Res. Lett., 33, L05711, doi:10.1029/ 2005 GL025032.

\section{Introduction}

[2] The North Atlantic Oscillation (NAO)/Arctic Oscillation (AO) and the Pacific/North American (PNA) pattern are the major winter climate modes of the interannual variability in the northern hemispheric midlatitudes. Changes in the phases of either pattern have marked impact on the regional climate. During extreme phases the NAO and the PNA are associated with the modulation of surface temperature, location and strength of storminess as well as the transport of moist air on largescale over the Atlantic-European area [Hurrell et al., 2003] and over the North Pacific and North America [Wallace and Gutzler, 1981].

[3] The variability of these dominant modes is largely described by internal processes of the midlatitude atmosphere and is inherently unpredictable. External processes originating from the Tropics, however, have a pronounced influence on their variability. For example, the variability of the PNA was found closely related to variations of warm ocean waters in the tropical Pacific [Trenberth et al., 1998], which is well known as El Niño/Southern Oscillation (ENSO [Philander, 1990]). The modulation of the phases of the NAO to such remote forcing of the Tropics, however, is less well understood. Observational and modeling studies provide evidence for a weak response of atmospheric

\footnotetext{
${ }^{1}$ Max-Planck Institute for Meteorology, Hamburg, Germany.
}

quantities and storm activity to ENSO [van Oldenborgh et al., 2000; Merkel and Latif, 2002]. More recently, there is evidence for a NAO-like response to forcing of the tropical Pacific [Lin et al., 2005; Pohlmann and Latif, 2005]. Others, however, also suggest a contribution by the Indian [Bader and Latif, 2003; Hoerling et al., 2001] or Atlantic Ocean [Sutton and Hodson, 2003].

[4] Given the important role of ENSO for the interannual variability in the tropics and extra-tropics, but also given the tendency of a warmer climate induced by anthropogenic greenhouse gas forcing, it is of particular interest how these extra-tropical circulation patterns are affected by ENSO in a changing climate. Several global climate models suggest a tendency of the Pacific climate to an "El Niño -like" state due to increased greenhouse gas forcing [Cubasch et al., 2001]. More explicitly some authors provide model evidence of an increase in ENSO activity in the future climate [Timmermann et al., 1999; Collins, 2000]. However, these results are still controversial and must be set into a broader context including the uncertainty of model formulation [Collins et al., 2005; van Oldenborgh et al., 2005]. Assuming a different state of ENSO in a changing climate the main issue of this paper is to estimate the dynamical response of the dominant patterns of the midlatitudes interannual variability. For this we use an ensemble of the latest IPCC climate change projections from the coupled climate model of the Max Planck Institute for Meteorology. Based on the IPCC Special Report on Emission Scenario (SRES) A1B the dynamical response is investigated for the 20th century and for the future (21st and 22 nd century) climate.

\section{Twentieth Century Climate}

[5] Monthly means of surface temperature and geopotential height at $500 \mathrm{hPa}$ of the ECMWF ERA40 Reanalysis data [Simmons and Gibson, 2000] and the Max-Planck Institute for Meteorology coupled atmosphere-ocean model have been used to describe the remote impact of the tropical Pacific. The model atmosphere is described by the latest cycle of the European Center/Hamburg Model Version 5 (ECHAM5) and is run at T63L31 resolution [Roeckner et al., 2003]. The ocean consists of the Max Planck Institute Ocean Model (MPI-OM) as described by Marsland et al. [2003]. Atmosphere and ocean are coupled by means of the OASIS coupler [Valcke et al., 2004] with no flux correction. A 500yr control simulation (CTRL) and 3 realizations of the 20th century simulations for the period 1900-2000 (20C) are considered. For the ERA40 Reanalysis we look at the period 1958-2001. Since ENSO/NAO show largest variability in winter our investigations are restricted to the winter (DJF) mean. 

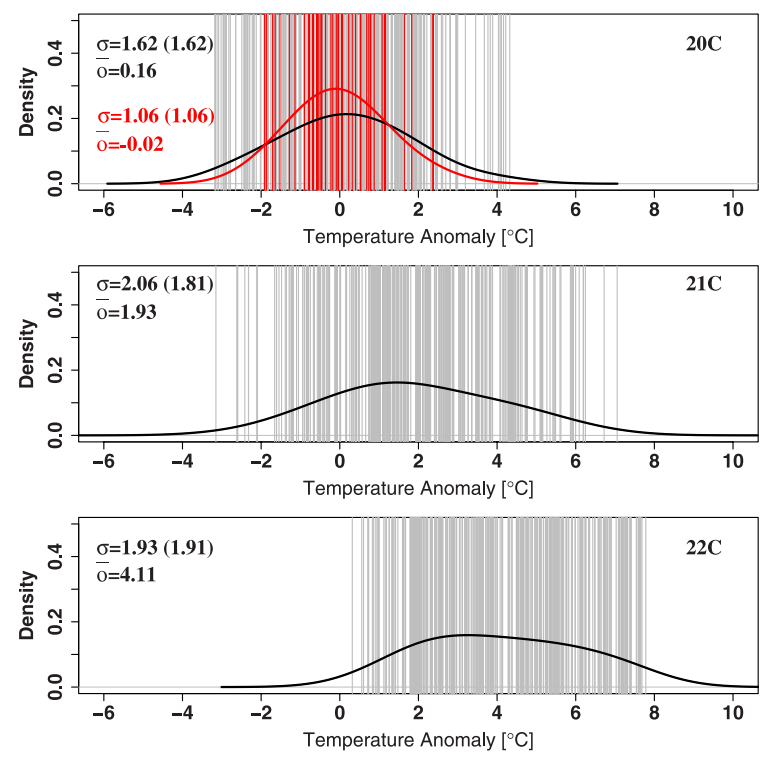

Figure 1. The winter mean Niño3.4 index (vertical lines) for (top) the ECMWF ERA40 reanalysis (red) and the ECHAM5/MPI-OM 20th century (20C) simulations (gray). The density estimations for ERA 40 and $20 \mathrm{C}$ are indicated in red and black, respectively. Indices and density estimations for the scenario A1B of the (middle) 21st century (21C) and (bottom) the stabilization runs of the 22nd century (22C). The indices of $20 \mathrm{C}, 21 \mathrm{C}$ and $22 \mathrm{C}$ are determined with respect to the 500yr control simulation (CTRL). The PDFs are obtained by a kernel density estimation based with a Gaussian window. Numbers show the mean value $(\overline{\mathrm{o}})$ and standard deviation $(\sigma)$ of ERA40 and model simulations. In brackets are the standard deviation of the time-series with the trend removed.

[6] The distributions of the winter mean Niño3.4 index (averaged SST anomaly over the region $5^{\circ} \mathrm{S}-5^{\circ} \mathrm{N}, 120^{\circ} \mathrm{W}-$ $170^{\circ} \mathrm{W}$ ) for the ERA40 Re-analysis and the $20 \mathrm{C}$ simulations are shown in Figure 1. The indices of the 20C simulations show a small shift in the mean state and larger variability than the ERA40 data. Although the amplitude is overestimated by a factor of 1.5 the period of the Niño3.4 index is realistically simulated with a dominant period of 4 years [Jungclaus et al., 2006; van Oldenborgh et al., 2005]. Figure 1 also indicates that for the 20C simulations the density of less likely events is estimated by more values than for the ERA40 data. This is important since we focus on extreme signals of the Niño3.4 index and investigate effects corresponding to the index greater (less) than plus 1 (minus -1) standard deviation, hereafter denoted as positive and negative events, respectively. For further analysis the indices and fields are determined with respect to the corresponding period and the trend removed.

[7] To analyze the contribution of the tropical forcing to the atmospheric circulation, composite maps are constructed as the difference of mean positive and mean negative events to the mean residuum (the residuum is defined as the set of those indices which are less (greater) than $1 \mathrm{sd}(-1 \mathrm{sd})$ ). Figure 2 shows the composite maps of the winter mean geopotential $500 \mathrm{hPa}$ for the $20 \mathrm{C}$ simulations associated with the positive and negative events, respectively. For positive events the midlatitude geopotential exhibits a strong signature over the North Pacific and North America with a strengthening of the Aleutian low. For the negative events the Aleutian low is weaker than normal and two weak anomalous highs are found in the southern US and northern midlatitude Atlantic. A similar analysis of the ERA40 data (not shown) reveals a more pronounced response than in the $20 \mathrm{C}$ simulations. Especially for the negative events a strong anomalous high is found over the European area. However, it must be noted that here only seven events are used (and 54 for all of the $20 \mathrm{C}$ simulations).

[8] To examine to what extent ENSO influences the dominant circulation patterns, the NAO and PNA indices of $20 \mathrm{C}$ and ERA40 are obtained with a regression of the corresponding fields of the geopotential at $500 \mathrm{hPa}$ on predefined NAO (PNA) patterns. The NAO (PNA) patterns are defined as the first EOF patterns of the geopotential at $500 \mathrm{hPa}$ of CTRL and ERA40 data, respectively, over the area of $100^{\circ} \mathrm{W}-60^{\circ} \mathrm{E}$ and $30^{\circ} \mathrm{N}-80^{\circ} \mathrm{N}\left(150 \mathrm{E}^{\circ}-30 \mathrm{~W}^{\circ}\right.$ and $20^{\circ} \mathrm{N}-80^{\circ} \mathrm{N}$ ). Pattern correlation between NAO (PNA) patterns of ERA40 and CTRL have significant values of $r=0.97(0.91)$. The correlation coefficients between the PNA indices and Niño3.4 indices show significant values of $\mathrm{r}=0.42$ and $0.26<\mathrm{r}<0.46$ for ERA40 and the $20 \mathrm{C}$ simulations, respectively (see Table 1). For the NAO index no statistically significant values are obtained $(\mathrm{r}=-0.12$ and $-0.13<\mathrm{r}<-0.01$ ). For each NAO (PNA) index the probability density functions (PDF) are calculated with respect to the positive and negative ENSO events. Figure 3 (top) shows the PDFs for the PNA and NAO for the 20C simulations. For the PNA index the PDFs resulting from positive and negative events are well separated.

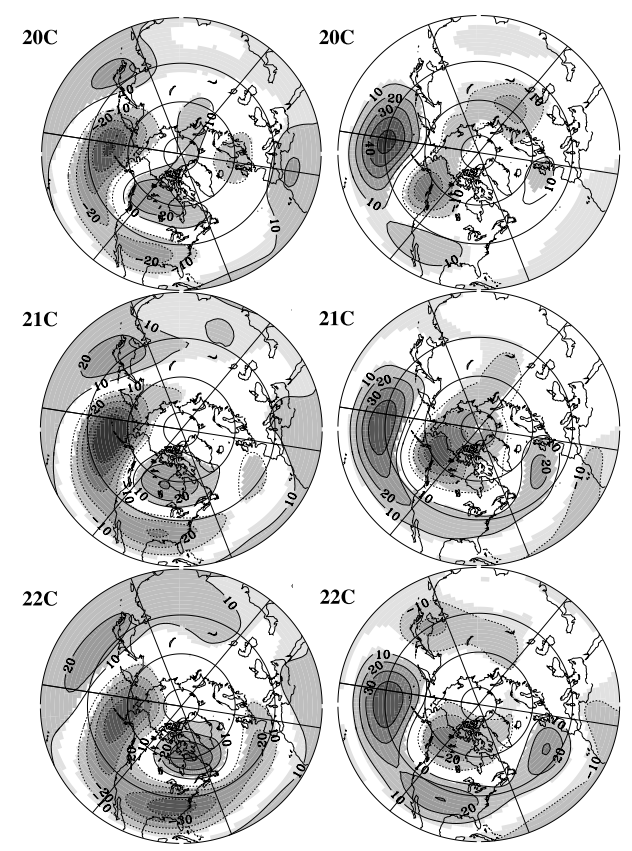

Figure 2. The composite maps of the geopotential at $500 \mathrm{hPa}$ for (left) El Niño $3.4>1$ sd and (right) El Niño3.4< $-1 \mathrm{sd}$ for the three realizations of the (top) 20C, (middle) 21C and (bottom) 22C simulation. Contour lines indicate $10 \mathrm{gdm}$. Negative values dashed. Significant areas at 95\% confidence level are shaded. 
Table 1. Correlation Coefficients $\left(\mathrm{r}_{\text {cor }}\right)$ of the Pearson Product Correlation Between the Winter Mean Niño3.4 Index and PNA (NAO) Index for All Realizations of the 20C, 21C, 22C, 500yr CTRL and the ERA40 Reanalysis ${ }^{\mathrm{a}}$

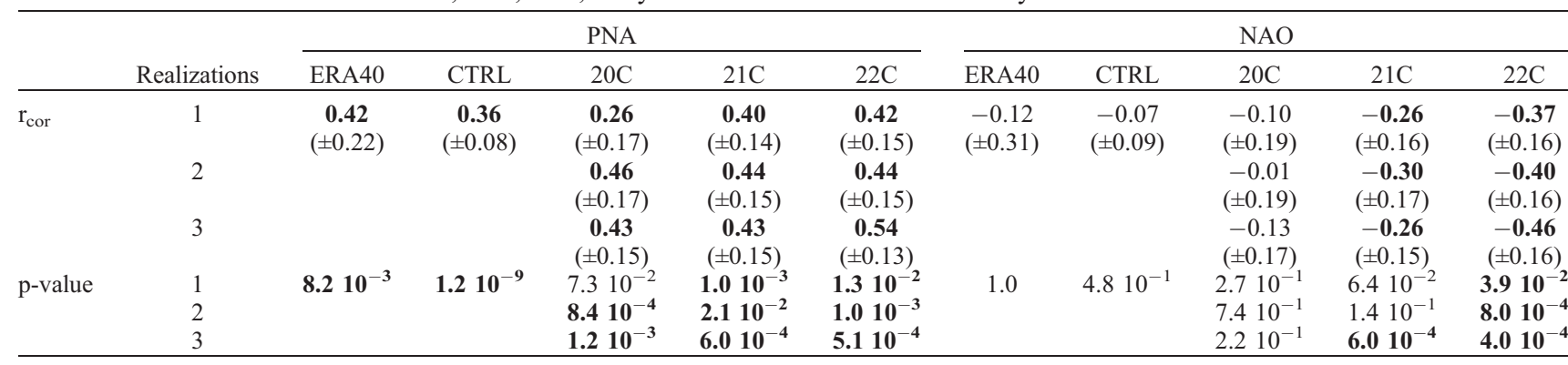

${ }^{a}$ Errors based on a bootstrap method (in brackets) indicate 95\% confidence interval. Further the p-values of the Kolmogorov-Smirnov test for the composites of the PNA and NAO indices. Significant values are given in bold.

Positive (negative) ENSO events are associated with a shift of PNA index to higher (lower) values. This is also found for the ERA40 data (not shown). Using a KolmogorovSmirnov (KS) test the distributions are statistically different for ERA40 and for two realizations of the 20C simulations, respectively (see Table 1 for p-values). For the NAO index the PDFs are not statistically different neither for the ERA40 nor the 20C simulation (see Table 1).

\section{Future Climate Change Projections}

[9] Similar to the previous section composite maps and PDFs are calculated for the IPCC SRES scenario A1B for the 21 st century $(21 \mathrm{C})$ and for an A1B stabilization scenario for the period 2100-2200 (22C). For the latter greenhouse gases and aerosols are fixed at their year 2100 level. A total of three realizations are available for each period.

[10] Figure 1 shows the Niño3.4 indices for the two periods. There is a strong shift toward higher positive values with mean values of $\bar{o}=1.93$ and $\bar{o}=4.01$ in the $21 \mathrm{C}$ and $22 \mathrm{C}$ simulations, respectively. Though this is to be expected as the global warming itself influences the indices, being temperatures, the shift of the mean state can also determined using the Southern Oscillation or related sea-level pressure indices [van Oldenborgh et al., 2005]. Moreover, the standard deviations of the time-series with the trend removed show a clear increase in variability of ENSO in the $21 \mathrm{C}$ and $22 \mathrm{C}$.

[11] Similar to the $20 \mathrm{C}$ climate the indices and fields are further determined with respect to the corresponding period and the trend removed. The composite maps of A1B for $21 \mathrm{C}$ and $22 \mathrm{C}$ for all realizations are shown in Figure 2. For positive and negative events an intensification of the existing pattern relative to the $20 \mathrm{C}$ simulation is found. For the positive events the minimum in the southeast of North America appears to be stronger and further elongated to the European continent in the $22 \mathrm{C}$ simulations. For the negative events the anomalous high from the south US to east Atlantic has steadily increased.

[12] As in the previous section for each realization of the $21 \mathrm{C}$ and $22 \mathrm{C}$ simulations the PNA and NAO index are calculated (via regression on the PNA and NAO pattern of CTRL). The correlation coefficients between the indices and the Niño3.4 index are shown in table 1. For the PNA index the $21 \mathrm{C}$ and $22 \mathrm{C}$ simulations show slightly higher coefficients than that of the 20th century simulation. For the NAO index, in contrast to the 20th century simulation, the correlation coefficients become statistically significant and vary between -0.30 and $-0.26(-0.46$ and -0.37$)$ for the $21 \mathrm{C}$ and $22 \mathrm{C}$ simulations, respectively.

[13] As in the 20th century simulation the PDFs are calculated with respect to the positive and negative ENSO events. Figure 3 shows the results for all realizations of A1B for $21 \mathrm{C}$ and $22 \mathrm{C}$. For the NAO the PDFs are steadily separated from the $21 \mathrm{C}$ to the $22 \mathrm{C}$ simulations indicating more negative (positive) NAO indices for positive (negative) ENSO events, respectively. The corresponding pvalues of the KS-test (Table 1) show an increase in the significantly different response of the NAO to positive and negative ENSO events. For the PNA the changes are less strong than for the NAO, but the PDFs are also further separated in the $21 \mathrm{C}$ and $22 \mathrm{C}$ simulations than in the $20 \mathrm{C}$.

\section{Summary and Discussion}

[14] In this paper we have investigated the remote impact of ENSO onto the dominant winter circulation patterns of
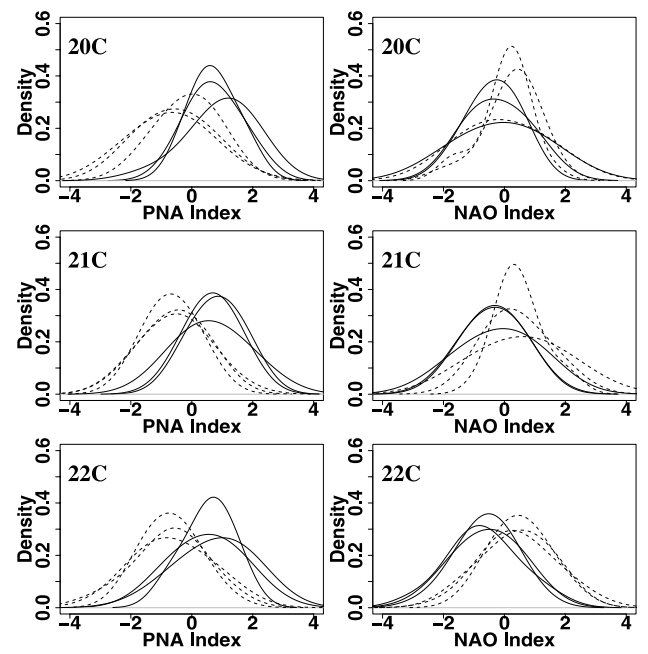

Figure 3. The probability density functions (PDFs) of (left) the PNA index and (right) the NAO index for the three realizations of the (top) $20 \mathrm{C}$, (middle) $21 \mathrm{C}$ and (bottom) 22C simulation. Solid (dashed) lines indicate indices with respect to positive (negative) Niño3.4 events. The PDFs are obtained by a kernel density estimation. 
the northern hemisphere in a future climate. Ensembles of future climate change projection as described by the IPCC SRES report are considered using the coupled atmosphereocean climate model ECHAM5/MPI-OM. It is found that within a changing state of ENSO a pronounced impact can be expected on the midlatitude flow, with most distinctive changes across the Atlantic Ocean. Moreover it is shown that a positive (negative) phase of ENSO is more likely followed by a positive (negative) PNA index and negative (positive) NAO index, respectively. Here particularly striking is the impact on the variability of the NAO index, which becomes significantly dependent on ENSO in the 21st and 22nd century climate change projections.

[15] Although there is increasing evidence of an interaction between ENSO and a NAO-like variability over the Atlantic Ocean, there are a number of possible mechanisms including indirect interactions via atmosphere-ocean teleconnections or a direct link via the stratosphere or troposphere, respectively. Concerning the latter a possible link could include changes in the storm track variability in the future climate (see also Bentgsson et al., 2006), which could either be altered by increasing teleconnectivity or modulation of the zonal flow such as the subtropical jet. For instance, for El Niño conditions the subtropical zonal wind is found to be significantly increased in the Atlantic and eastern Pacific in the future climate. But also since our results are given in the context of ENSO in a changing mean state, other factors such as the changing of the background state may be of relevance.

[16] Further, although the model fairly represents ENSO [Jungclaus et al., 2006], the above results rely on a proper estimation of the future state of ENSO, which is in turn limited by uncertainties such as model formulation and future concentrations of greenhouse gases and aerosols. To reduce uncertainties due to model formulation for instance, a higher number of models or multi-model simulation can be considered, as shown by Collins et al. [2005] and van Oldenborgh et al. [2005]. Uncertainties due to the future greenhouse gas forcing can be tackled by using several emission scenarios. For this we also examined the B1 scenario (not shown), and found that the results are similar to that of A1B scenario, but less significant.

[17] Finally the results are of particular interest for the long-range forecasts in the sphere of the circulation patterns. Since ENSO provides the major source of interannual variability in the Tropics with enhanced predictability several seasons ahead [Latif et al., 1998], a stronger impact on to the dominant extra-tropical circulation patterns might also affect the corresponding forecast skill, for instance for the NAO for which today's forecast skill is limited [Müller et al., 2005].

[18] Acknowledgments. We thank T. Nozawa, G. Jones, E. Kaas, J.-F. Royer, and G. Strand for providing data. Special thanks to F. Sienz, P. Lorenz, M. Botzet and J. Bader for their comments on the original manuscript. This research was financed in part by the German Ministry for Education and Research (BMBF) under the DEKLIM Project and by the European Community under the ENSEMBLES Project. The model simulations were done at the German Climate Computing Center (DKRZ) in Hamburg.

\section{References}

Bader, J., and M. Latif (2003), The impact of decadal-scale Indian Ocean sea surface temperature anomalies on Sahelian rainfall and the North Atlantic Oscillation, Geophys. Res. Lett., 30(22), 2169, doi:10.1029/ 2003 GL018426.

Bentgsson, L., K. Hodges, and E. Roeckner (2006), Storm tracks and climate change, J. Clim., in press.

Collins, M. (2000), Understanding uncertainties in the response of ENSO to greenhouse warming, Geophys. Res. Lett., 27, 3509-3513.

Collins, M., et al. (2005), El Niño- or La Niña-like climate change?, Clim. Dyn., 24, 89-104.

Cubasch, U., et al. (2001), Projections of future climate change, in Climate Change 2001: The Scientific Basis. Contribution of Working Group I to the Third Assessment Report of the Intergovernmental Panel on Climate Change, edited by J. T. Houghton et al. pp. 526-582, Cambridge Univ. Press, New York.

Hoerling, M. P., J. W. Hurrell, and T. Xu (2001), Tropical origins for recent North Atlantic climate change, Science, 292, 90-92.

Hurrell, J., Y. Kushnir, G. Ottersen, and M. Visbeck (2003), An overview of the North Atlantic Oscillation, in The North Atlantic Oscillation: Climatic Significance and Environmental Impact, Geophys. Monogr. Ser., vol. 134, edited by J. W. Hurrell et al., pp. 1-36, AGU, Washington, D. C.

Jungclaus, J. H., M. Botzet, H. Haak, N. Keenlyside, J.-J. Luo, M. Latif, J. Marotzke, U. Mikolajewicz, and E. Roeckner (2006), Ocean circulation and tropical variability in the coupled model ECHAM5/MPIOM, J. Clim., in press.

Latif, M., D. Anderson, M. Cane, R. Kleeman, A. Leetmaa, J. O’Brien, A. Rosati, and E. Schneider (1998), A review of the predictability and prediction of ENSO, J. Geophys. Res., 103, 14,375-14,393.

Lin, H., J. Derome, and G. Brunet (2005), Tropical Pacific link to the two dominant patterns of atmospheric variability, Geophys. Res. Lett., 32, L03801, doi:10.1029/2004GL021495.

Marsland, S. J., H. Haak, J. H. Jungclaus, M. Latif, and F. Röske (2003), The Max-Planck Institute global ocean/sea ice model with orthogonal curvilinear coordinates, Ocean Modell., 5, 91-127.

Merkel, U., and M. Latif (2002), A high resolution AGCM study of the El Niño impact on the North Atlantic/European sector, Geophys. Res. Lett., 29(9), 1291, doi:10.1029/2001GL013726.

Müller, W. A., C. Appenzeller, and C. Schär (2005), Probabilistic seasonal prediction of the winter North Atlantic Oscillation and its impact on near surface temperature, Clim. Dyn., 24, 213-226.

Philander, S. G. H. (1990), El Nino, La Niña, and the Southern Oscillation, 289 pp., Elsevier, New York.

Pohlmann, H., and M. Latif (2005), Atlantic versus Indio-Pacific influence on Atlantic-European climate, Geophys. Res. Lett., 32, L05707, doi:10.1029/2004GL021316.

Roeckner, E., et al. (2003), The atmosphere general circulation model ECHAM5, part I: Model description, Rep. 349, 127 pp., Max-Planck Inst. für Meteorol., Hamburg, Germany.

Simmons, A. J., and J. K. Gibson (2000), The ERA40 Project plan, ERA-40 Rep. Ser. 1, 63 pp., Eur. Cent. for Medium-Range Weather Forecasts, Reading, U. K.

Sutton, R. T., and D. L. R. Hodson (2003), Influence of the ocean on North Atlantic climate variability 1871-1999, J. Clim., 16, 3296-3313.

Timmermann, A., J. Oberhuber, A. Bacher, M. Esch, M. Latif, and E. Roeckner (1999), Increased El Nino frequency in a climate model forced by greenhouse warming, Nature, 398, 694-697.

Trenberth, K. E., et al. (1998), Progress during TOGA in understanding and modelling global teleconnections associated with tropical sea surface temperature, J. Geophys. Res., 103, 14,291-14,324.

Valcke, S., A. Caubel, D. Declat, and L. Terray (2004), OASIS Ocean Atmosphere Sea Ice Soil user's guide, Tech. Rep. TR/CMGC/03/69, Cent. Eur. de Rech. et de Formation Avancée en Calcul Sci., Toulouse, France. van Oldenborgh, G. J., G. Burgers, and A. Klein Tank (2000), On the El Nino teleconnection to spring precipitation in Europe, Int. J. Clim., 20, 565-574.

van Oldenborgh, G. J., S. Philip, and M. Collins (2005), El Nino in a changing climate: A multi-model study, Ocean Sci., 1, 81-95.

Wallace, J. M., and D. Gutzler (1981), Teleconnections in the geopotential height field during the Northern Hemisphere winter, Mon. Weather Rev, 109, 784-812.

E. Roeckner and W. A. Müller, Max-Planck Institute for Meteorology, Budesstrasse 53, D-20257 Hamburg, Germany. (wolfgang.mueller@ dkrz.de) 